\title{
Cracks and Fractures in Teeth
}

\author{
${ }^{1}$ Angambakkam R PradeepKumar, ${ }^{2}$ Arunajatesan Subbiya
}

\begin{abstract}
Cracks and fractures in teeth are difficult to diagnose and treat, especially in the initial stages. The etiology of cracks is still obscure. With an increase in both geriatric population and tooth retention, the incidence of cracked teeth can also increase. There are many types of cracks from simple craze lines to vertical root fracture. An astute clinician should make crack detection a part of diagnostic screening. Proper diagnosis and treatment of cracked teeth is not possible without knowledge of the types of cracks along with associated signs and symptoms. This review presents a brief introduction to the various types of cracks and will aid the clinician in crack identification and management.
\end{abstract}

Keywords: Cracked tooth, Fractured cusp, Vertical root fracture. How to cite this article: PradeepKumar AR, Subbiya A. Cracks and Fractures in Teeth. J Oper Dent Endod 2017;2(1):25-30.

Source of support: Nil

Conflict of interest: None

\section{INTRODUCTION}

Cracked tooth represents a diagnostic challenge. The evaluation of the extent of a crack and the treatment of these cracks and fractures can also be difficult. Cracked teeth can have complicated or vague symptoms. ${ }^{1}$ The cracked tooth along with its associated signs and symptoms is referred to was "cracked tooth syndrome" by Cameron. ${ }^{2}$ However, the word syndrome usually refers to a combination of factors, signs, and symptoms which when collectively viewed confirm the existence of a specific disease. This may not be the case with the signs and symptoms accompanying a cracked tooth, and the use of the term "syndrome" is nowadays avoided. ${ }^{3}$ The prognosis is usually guarded and depends on the extent of the crack. ${ }^{4}$ These cracks are mainly longitudinal and usually originate from the crown of the tooth. Cracks and fractures originating in the root can be a vertical root fracture (VRF) which is one of the most catastrophic complications after root canal

\footnotetext{
${ }^{1,2}$ Professor and Head

${ }^{1}$ Department of Conservative Dentistry and Endodontics, Thai Moogambigai Dental College and Hospital, Chennai, Tamil Nadu, India

${ }^{2}$ Department of Conservative Dentistry and Endodontics, Sree Balaji Dental College \& Hospital, Chennai, Tamil Nadu, India

Corresponding Author: Angambakkam R PradeepKumar Professor and Head, Department of Conservative Dentistry and Endodontics, Thai Moogambigai Dental College and Hospital Chennai, Tamil Nadu, India, Phone: +914426424797, e-mail: arpradeep@vsnl.com
}

treatment. ${ }^{1}$ This review deals mainly with coronal cracks and fractures which are not related to trauma and related etiology. These cracks and fractures may extend over time either along the long axis of the tooth or vertically at an angle to the long axis. A crack or fracture is a finding and not a diagnosis ${ }^{1}$ as it may or may not be associated with pathology which needs to be confirmed by further tests. The presence of a crack will have to be detected as part of a clinical examination. Cracks and fractures can serve as a route for bacterial penetration which can result in pulpal disease. A crack has been defined as a surface discontinuity which may develop into a fracture which can have actual separation of fragments. ${ }^{5}$ As patients live longer and retain their teeth for a longer period of time, the incidence of cracks may also increase. ${ }^{1}$

For convenience, the terms crack and fracture will be used interchangeably in this review.

Types of cracks in teeth according to the American Association of Endodontics (AAE) ${ }^{1}$ are as follows:

- Craze lines

- Fractured cusp

- Cracked tooth

- Split tooth

- VRF

\section{Craze Lines}

Craze lines usually involve only enamel. They can be present in occlusal surfaces or on buccal and lingual surfaces. They are asymptomatic and do not require treatment unless there is an esthetic concern. Transillumination is done to differentiate a craze line from a cracked tooth. If the light is blocked by the line it is most probably a crack and if the light illuminates the entire crown it is a craze line. ${ }^{1}$

\section{Fractured Cusp}

When a cusp is separated from the rest of the tooth by a complete or an incomplete fracture it is termed as a fractured cusp. They may or may not be associated with facial trauma. Such fractures usually originate from the occlusal surface and extend to the cervical aspect of the tooth or root. They may be associated with a large restoration or extensive caries. There may be pain on release of bite and percussion. The pulp may or may not be affected. Supragingival fractures have a better prognosis than subgingival fractures. They are relatively easy to 
diagnose. The affected cusp is removed and the remaining tooth structure is restored. If the fracture involves the pulp, root canal treatment will be necessary. ${ }^{1}$ Bader et $\mathrm{al}^{6}$ have reported on cusp fractures. They reported that most of such fractures resulted in dentin exposure but very few caused pulp exposure. Most of the teeth with cusp fractures were associated with restored teeth. In their survey, they found that lingual cusps fractured more frequently than buccal cusps in mandibular molars and that buccal cusps fractured more often in maxillary premolars. In maxillary molars, the mesiobuccal and distolingual cusps fractured most frequently. They also reported that subgingival extension of the fracture was not common and that most of the teeth were vital.

\section{Cracked Tooth}

A cracked tooth has an incomplete crack originating coronally and extending cervically (Fig. 1). They occur commonly in mandibular molars. ${ }^{4}$ The crack is usually centrally located and can cross one or both marginal ridges and may extend into the proximal surfaces. ${ }^{1}$ These cracks are usually present mesiodistally. However, Seo et $\mathrm{al}^{7}$ have reported that cracks can also occur buccolingually or can be both in the mesiodistal and in the buccolingual directions. Similarly, Roh and Lee ${ }^{8}$ have reported that the most common direction of cracks was mesiodistal but cracks can also occur in the buccolingual direction or in both directions. They may occur in intact teeth $^{4}$ or in restored teeth where they are seen in the unrestored part of the tooth or in the cavity floor after removal of the restoration or both. They can be identified by staining and transillumination. However, early identification may be difficult. Pain on mastication can be present. According to Seo et $\mathrm{al}^{7}$ the bite test is the most reliable for identifying a cracked tooth. If the crack involves the pulp, pulpal pathology and symptoms

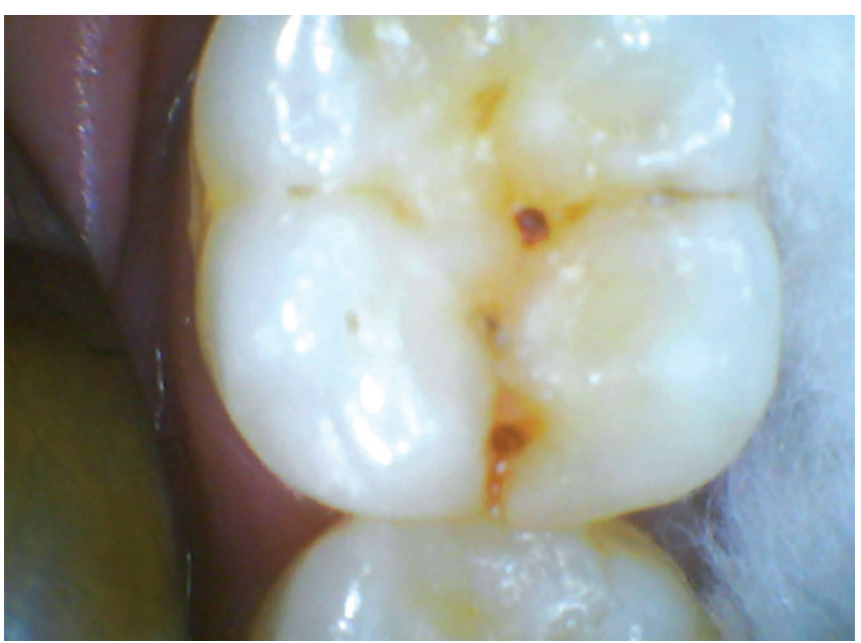

Fig. 1: Occlusal aspect of mandibular first molar showing mesial crack occur. A deep narrow pocket may be seen. The tooth can be conservatively treated using resin restorations if there are no signs or symptoms of irreversible pulpitis. ${ }^{4}$ However, they will have to be reviewed periodically. Deeper cracks involving the pulp will require root canal treatment. Cracks may also extend to the pulpal floor or to the root. ${ }^{9}$

\section{Split Tooth}

A cracked tooth can become a split tooth. This happens when the crack deepens and the incomplete crack widens with separation of fragments. Such teeth have a hopeless prognosis and may be extracted.

\section{Predisposing Factors}

Cracks are more commonly seen in posterior teeth and with an increase in age. According to Kang et al, ${ }^{4}$ mandibular molars are more commonly affected by cracks. Similar predilection for mandibular molars was also reported by Hiatt. The reason for this might be that these teeth are closer to the temporomandibular joint. Due to the lever effect, it is hypothesized that teeth closer to the temporomandibular joint may be affected by more masticatory stress. The anatomy of molar teeth has also been implicated. An ideal cusp-fossa relationship may result in compressive stresses on the cusp and tensile stress in the fossa. These forces may result in the creation of cracks in the fossa. The fossa may be weaker as this is the region where zones of calcification coalesce. ${ }^{10}$ The lingual cusps of maxillary teeth may act as a plunger and result in excess force on mandibular teeth leading to failure. Also, the presence of an oblique ridge in maxillary teeth may increase their resistance to fracture. ${ }^{11}$ However, Roh and Lee ${ }^{8}$ have reported that cracks are more prevalent in maxillary molars. They have reported that lingually tilted mandibular molars are present in the Korean population and the buccal cusps of these molars may act as plunger cusps to maxillary molars. Increase in age can be a predisposing factor. Kang et $\mathrm{al}^{4}$ reported more numbers of cracked teeth in patients aged more than 50 years. Seo et $\mathrm{al}^{7}$ found that the majority of patients with cracks were aged between 40 and 50 years. They also found that there were very few patients with cracked teeth who were aged between 60 and 70 years and they attributed this to earlier treatment or a reduction in the number of teeth. Ratcliff et $\mathrm{al}^{5}$ reported that the majority of cracked posterior teeth in their study occurred in patients between the ages of 40 and 49 years. They also reported that excursive interferences and parafunction may increase the incidence of cracks in posterior teeth. Roh and Lee ${ }^{8}$ have reported the prevalence of cracks is more above 40 years of age. 


\section{Gender}

Gender as a predisposing factor was evaluated by many authors with no specific predilection. Roh and Lee ${ }^{8}$ have reported that the incidence of cracks was similar in males and females. Similar results were reported by Seo et al. ${ }^{7}$ However, Kang et $\mathrm{al}^{4}$ have reported that cracks are more common in males (61\%).

\section{Diagnosis}

In the initial stages, a cracked tooth will give nonspecific symptoms. Pain on biting or mastication can be present. An initial crack may not be visible even after staining. ${ }^{1}$ Magnification, staining, transillumination, and the bite test are very useful in the early diagnosis of cracks. It is much easier to diagnose when the crack progresses into a fracture. If the tooth is restored, it may be necessary to remove all restorations to achieve a diagnosis. Magnification using loupes or a dental operating microscope is a useful adjunct in diagnosis especially after dye application. Methylene blue dye is one of the commonly used dyes. It is applied to the tooth surface and the excess dye can be wiped away with $70 \%$ isopropyl alcohol. Dye, which has penetrated into the crack, will indicate crack location. ${ }^{1}$ Transillumination using a fiberoptic light probe is very useful. The light beam is directed through the tooth structure perpendicular to the estimated fracture plane. Light travels through the tooth, but will not be effectively transmitted through the fracture with a resulting abrupt change in light intensity at the fracture. ${ }^{12}$ Another clinical test which can be done to evaluate a tooth with a suspected crack is the bite test. Bite tests are indicated whenever the patient complains of pain during mastication or biting. Bite tests will be positive when pulpal pathosis has extended to the periodontal ligament resulting in symptomatic apical periodontitis or can be secondary to a crack in the tooth. Cotton rolls, rubber polishing wheels, or devices like the tooth slooth are used to apply pressure on individual cusps in posterior teeth. In symptomatic apical periodontitis, pain will be present when percussion or pressure is applied on any part of the occlusal surface. However, a cracked tooth will respond with pain on percussion or pressure in certain directions or areas on the occlusal surface. ${ }^{2}$ Pain on release of pressure is also a common finding in a cracked tooth. ${ }^{3}$ According to Seo et al, ${ }^{7}$ the bite test is reliable in reproducing the symptoms of a cracked tooth. Similarly, Roh and Lee ${ }^{8}$ have also reported that the bite test is accurate in the diagnosis of cracks in teeth. In some cases, especially when there is an unexplained sinus tract, it may be indicated to perform diagnostic surgery to evaluate cervical tooth and root surfaces for cracks. Radiographs may not have a significant role in the diagnosis of coronal cracks. In later stages when there is separation of fragments, it may be visible in radiographs. Vertical bone loss or furcation bone loss may indicate a deep crack. Otherwise, radiographic findings depend on the pulpal and periradicular status of the tooth. ${ }^{1}$ Similarly, sensibility testing is also not diagnostic for cracks. A crack may be present irrespective of the pulpal status of the tooth.

\section{Restorations and Cracks}

Kang et $\mathrm{al}^{4}$ reported cracked teeth to be more common in intact teeth. However, Seo et $\mathrm{al}^{7}$ reported cracks mainly in restored teeth. They also reported that teeth restored with amalgam and inlays may be more prone to cracks which may be due to sharp line angles in cavity preparation. They reported less cracks in teeth with resin or porcelain restorations. They hypothesized that cracks may form due to occlusal stress as well as a mismatch between the thermal expansion coefficient between the tooth and the restorative material. Ratcliff et $\mathrm{al}^{5}$ have reported that class I and II restorations were associated with cracks in posterior teeth. They have hypothesized that restorations can put teeth at a greater risk for fracture. However, Roh and Lee ${ }^{8}$ have reported that in their study of 154 teeth with cracks in a Korean population, cracks were more common in intact molar teeth or in teeth with class I restorations. Similarly, Hiatt ${ }^{10}$ has reported that cracks more commonly occur in teeth without restorations or in teeth with class I restorations. Berman and Kuttler ${ }^{13}$ have reported on "fracture necrosis," a type of cracked tooth with pulpal necrosis which is unrestored or minimally restored. Therefore, it is generally accepted that cracks can occur in teeth with restorations as well as in teeth without a restoration.

\section{Treatment}

Craze lines are to be monitored to evaluate whether they develop into future cracks. Once a crack is identified, treatment usually consists of removal of cracked tooth portions and restoration with bonded restorations or a cuspal-coverage restoration. ${ }^{1}$ Treatment also depends on the depth of the crack. When the only complaint is biting sensitivity, banding the tooth may alleviate the symptoms. If so, the band can be replaced by a crown. ${ }^{1}$ When there is pulpal involvement, root canal treatment is done followed by an adequate postendodontic restoration. The prognosis is guarded. Berman and Kuttler ${ }^{13}$ have recommended extraction for teeth with pulpal necrosis secondary to a longitudinal crack or fracture. Kang et $\mathrm{al}^{4}$ have evaluated root canal treatment in cracked teeth and have reported a 2-year survival rate of $90 \%$. Cracked teeth associated with 
deep periodontal pockets may have a poor prognosis. Sim et $\mathrm{al}^{9}$ have reported a $92 \%$ survival rate of cracked teeth after root canal treatment and found that teeth with cracks in the pulpal floor have a poor prognosis. Further research in evaluation of crack depth and treatment of cracked teeth is necessary to formulate predictable treatment options.

\section{Vertical Root Fracture}

As opposed to coronal cracks, there are cracks in the root that are termed as VRF. These are different from horizontal or oblique fractures which can happen due to trauma. According to the AAE, VRF has been defined as a complete or incomplete fracture initiated from the root and is usually in a buccolingual direction (Fig. 2). Vertical root fracture may involve only one surface (buccal or lingual) or both buccal and lingual root surfaces. The fracture is usually located in the root portion of the tooth only. Vertical root fracture may extend the length of the root or occur as a shorter crack at any level along the root. ${ }^{1}$ It may lead to extraction of the affected root or tooth and can be associated with a history of root canal treatment. ${ }^{14}$

\section{Prevalence}

The prevalence of VRF after endodontic treatment has been reported by various authors. The clinical picture of VRF may be similar to pulpoperiodontal disease or to a failed root canal treatment. Morfis ${ }^{15}$ has reported a prevalence of $3.69 \%$ after reviewing 460 endodontically treated teeth for 3 years. Vire ${ }^{16}$ evaluated reasons for failure of endodontically treated teeth and reported VRF in $4.3 \%$. Fuss et $\mathrm{al}^{17}$ reported a prevalence of $11 \%$, while Touré et $\mathrm{al}^{18}$ reported $13.4 \%$. Coppens and DeMoor ${ }^{19}$ reported $20 \%$, while Borén et $\mathrm{al}^{20}$ reported $6 \%$ of VRF when analyzing failed endodontically treated teeth. This wide variation in the reported prevalence may be

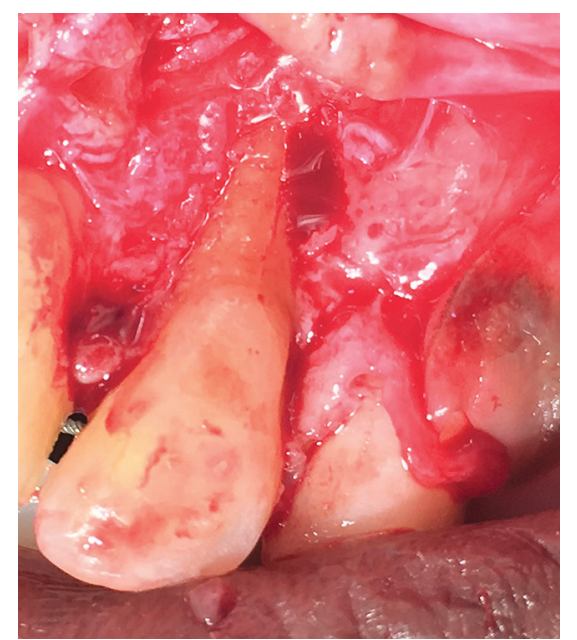

Fig. 2: Palatal aspect of maxillary lateral incisor showing VRF in the midbuccal aspect due to the varying clinical presentation and the difficult diagnosis of VRF. ${ }^{21}$

\section{Predisposing Factors}

Vertical root fracture can occur in endodontically treated teeth as well as in nonendodontically treated teeth. ${ }^{22}$ Tang et $\mathrm{a}^{14}$ have reported that VRF mainly occurs in endodontically treated molar teeth, while Cohen et $\mathrm{al}^{22}$ have reported that VRF is more common in mandibular molars and maxillary premolars. It has been reported that older patients ( $>40$ years) with overfilled root canals can predispose to VRF. ${ }^{21}$ Roots which are flattened mesiodistally have been reported to be prone to VRF. ${ }^{23}$

\section{Age and VRF}

Aging may alter the mechanical behavior as well as the mechanical properties of dentin. Aging is accompanied by an increase in the thickness of both coronal and radicular dentin. The dentinal tubules also exhibit marked changes with an increase in mineral deposition within tubule lumens with a corresponding reduction in tubule diameters. When a sufficient number of tubules have been filled, dentin appears transparent and this change is referred to as sclerotic dentin. ${ }^{24}$ Thomas et $\mathrm{al}^{25}$ have reported that sclerotic dentin is more prominent in teeth which have undergone endodontic treatment independent of the patients' age. It has been reported that dentin becomes more brittle with age. Dentin from older patients ${ }^{26}$ can have a reduction in flexural strength as well as a reduction in energy required to fracture. Fatigue strength can also reduce with age. Kinney et $\mathrm{al}^{27}$ have reported that sclerotic dentin exhibited lower fracture toughness. The perceived change in the mechanical properties of older dentin may not be only due to mineral deposits in the dentin tubules. Changes in collagen cross-linking ${ }^{28}$ are important and can also play a role. These age-related dentin changes will have to be considered while performing endodontic treatment in older individuals.

\section{Clinical Signs and Symptoms}

Early diagnosis of VRF is crucial to conserve remaining bone in that region which may optimize future restoration of that area. Vertical root fracture may occur during intracanal procedures like obturation or post placement. However, signs and symptoms of VRF may occur years after the completion of endodontic procedures. ${ }^{29}$ The presence of deep, narrow periodontal pockets and a "halo" radiolucency can be indicative of a VRF. ${ }^{21}$ Deep, narrow pockets are seen in VRF as opposed to broad-based pockets seen in periodontal disease. Periodontal tissue breakdown can happen due to necrotic debris and bacteria in the fracture, which can form a deep periodontal pocket. ${ }^{30}$ 


\section{Radiographs and Cone Beam Computed Tomography in VRF}

Radiographs and cone beam computed tomography (CBCT) are adjuncts in the diagnosis of VRF. It has been shown that in order to visualize a VRF the primary beam of the X-ray must be within $4^{\circ}$ of the fracture plane. ${ }^{31}$ In late stages of VRF, when there is separation of fragments, it will be apparent in radiographs. One of the common radiographic findings in VRF is a "halo"-shaped radiolucency that may be seen as a periradicular rarefaction/ radiolucency on the lateral aspect of the affected root, which extends apically and to other sides of the root. ${ }^{23}$

Computerized tomography was introduced Sir Godfrey Hounsfield in which images of thin slices of anatomy are captured and synthesized to obtain information in three dimensions. This was followed by the introduction of CBCT which was faster, with a lower radiation dose. Cone beam computed tomography is the imaging modality of choice for challenging diagnostic situations. Evaluating an endodontically treated tooth for the presence of VRF is one of the indications for CBCT imaging. ${ }^{32}$ However, the interpretation of this image is challenging due to the presence of obturating materials. ${ }^{33}$ It has been reported that both digital radiography ${ }^{34}$ and CBCT have limitations in the diagnosis of early VRF. Cone beam computed tomography may be an useful adjunct to a meticulous clinical examination as it could reveal subtle changes in the periradicular bone around the fracture before the actual fracture becomes visible. Cone beam computed tomography can also visualize bone destruction before it involves the cortical plate. For a VRF to be visible in a CBCT the width of the fracture should be double the voxel size of the machine. ${ }^{35}$ The maximum width of natural fractures was reported to range from 60 to $770 \mu \mathrm{m} .{ }^{34}$ A recent review has concluded that there is currently insufficient evidence to suggest that CBCT is a reliable test in detecting VRF in endodontically treated teeth. ${ }^{36}$ The "gold standard" for identification of a VRF would be either direct visualization of the fracture line on the root surface after surgical exploration ${ }^{21}$ or intracanal visualization of the fracture line using a dental operating microscope.

\section{Treatment}

The treatment for VRF is extraction of the tooth or root. As VRF can result in loss of bone around the cracked root, early diagnosis and treatment can help in conservation of bone which will help in future restoration of that area.

\section{CONCLUSION}

Cracks and fractures are difficult to identify especially in the initial stages. It is necessary to be aware of the presence of cracks in teeth. Identification of craze lines and cracks is part of a thorough intraoral examination. Cracks in teeth are to be considered whenever a patient complains of pain during mastication. If a crack is suspected, the steps outlined in this article can be used for help in identification, classification, and management of the cracked tooth or root.

\section{REFERENCES}

1. American Association of Endodontists. Cracking the cracked tooth code: detection and treatment of various longitudinal tooth fractures. In: Endodontics: colleagues for excellence. 2008. p. 1-8. [cited 2016 Mar 20]. Available from: https://www.aae. org/uploadedfiles/publications_and_research/endodontics_ colleagues_for_excellence_newsletter/ecfesum08.pdf.

2. Cameron CE. The cracked tooth syndrome: additional findings. J Am Dent Assoc 1976 Nov;93(5):971-975.

3. Berman, LH.; Rotstein, I. Diagnosis. In: Hargreaves K, Berman L, editors. Cohen's pathways of the pulp. First South Asia ed. St. Louis: Elsevier; 2016. p. 2-32.

4. Kang SH, Kim BS, Kim Y. Cracked teeth: distribution, characteristics, and survival after root canal treatment. J Endod 2016 Apr;42(4):557-562.

5. Ratcliff S, Becker IM, Quinn L. Type and incidence of cracks in posterior teeth. J Prosthet Dent 2001 Aug;86(2):168-172.

6. Bader, JD, Martin JA, Shugars DA. Incidence rates for complete cusp fracture. Community Dent Oral Epidemiol 2001 Oct;29(5):346-353.

7. Seo DG, Yi YA, Shin SJ, Park JW. Analysis of factors associated with cracked teeth. J Endod 2012 Mar;38(3):288-292.

8. Roh BD, Lee YE. Analysis of 154 cases of teeth with cracks. Dent Traumatol 2006 Jun;22(3):118-123.

9. Sim IG, Lim TS, Krishnaswamy G, Chen NN. Decision making for retention of endodontically treated posterior cracked teeth: a 5-year follow-up study. J Endod 2016 Feb;42(2):225-229.

10. Hiatt WH. Incomplete crown-root fracture in pulpal-periodontal disease. J Periodontol 1973 Jun;44(6):369-379.

11. Ehrmann BH, Tyas MJ. Cracked tooth syndrome: diagnosis, treatment and correlation between symptoms and postextraction findings. Aust Dent J 1990 Apr;35(2):105-112.

12. Pitts DL, Natkin E. Diagnosis and treatment of vertical root fractures. J Endod 1983 Aug;9(8):338-346.

13. Berman LH, Kuttler S. Fracture necrosis: diagnosis, prognosis assessment, and treatment recommendations. J Endod 2010 Mar;36(3):442-446.

14. Tang $\mathrm{W}, \mathrm{Wu} \mathrm{Y}$, Smales RJ. Identifying and reducing risks for potential fractures in endodontically treated teeth. J Endod 2010 Apr;36(4):609-617.

15. Morfis AS. Vertical root fractures. Oral Surg Oral Med Oral Pathol Oral Radiol Endod 1990 May;69(5):631-635.

16. Vire DE. Failure of endodontically treated teeth: classification and evaluation. J Endod 1991 Jul;17(7):338-342.

17. Fuss Z, Lustig J, Tamse A. Prevalence of vertical root fractures in extracted endodontically treated teeth. Int Endod J 1999 Aug;32(4):283-286.

18. Touré B, Faye B, Kane AW, Lo CM, Niang B, Boucher Y. Analysis of reasons for extraction of endodontically treated teeth: a prospective study. J Endod 2011 Nov;37(11):1512-1515.

19. Coppens CRM, DeMoor RJG. Prevalence of vertical root fractures in extracted endodontically treated teeth. Int Endod J 2003;36:926. 
20. Borén DL, Jonasson P, Kvist T. Long-term survival of endodontically treated teeth at a public dental specialist clinic. J Endod 2015 Feb;41(2):176-181.

21. PradeepKumar AR, Shemesh H, Jothilatha S, Vijayabharathi R, Jayalakshmi S, Kishen A. Diagnosis of vertical root fractures in restored endodontically treated teeth: a time-dependent retrospective cohort study. J Endod 2016 Aug;42(8): 1175-1180.

22. Cohen S, Berman LH, Blanco L, Bakland L, Kim JS. A demographic analysis of vertical root fractures. J Endod 2006 Dec;32(12):1160-1163.

23. Tamse A, Kaffe I, Lustig J, Ganor Y, Fuss Z. Radiographic features of vertically fractured endodontically treated mesial roots of mandibular molars. Oral Surg Oral Med Oral Pathol Oral Radiol Endod 2006 Jun;101(6):797-802.

24. Arola D, Ivancik J, Majd H, Fouad A, Bajaj D, Zhang XY, Eidelman N. Microstructure and mechanical behaviour of radicular and coronal dentin. Endod Topics 2009 Mar;20(1):30-51.

25. Thomas GJ, Whittaker DK, Embery G. A comparative study of translucent apical dentine in vital and non-vital human teeth. Arch Oral Biol 1994 Jan;39(1):29-34.

26. Arola D, Reprogel RK. Effects of aging on the mechanical behavior of human dentin. Biomaterials 2005 Jun;26(18): 4051-4061.

27. Kinney JH, Nalla RK, Pople JA, Breunig TM, Ritchie RO. Age-related transparent root dentin: mineral concentration, crystallite size, and mechanical properties. Biomaterials 2005 Jun;26(16):3363-3376.
28. Rivera EM, Yamauchi M. Site comparisons of dentine collagen cross-links from extracted human teeth. Arch Oral Biol 1993 Jul;38(7):541-546.

29. Fuss Z, Lustig J, Katz A, Tamse A. An evaluation of endodontically treated vertical root fractured teeth: impact of operative procedures. J Endod 2001 Jan;27(1):46-48.

30. Walton RE, Michelich RJ, Smith GN. The histopathogenesis of vertical root fractures. J Endod 1984 Feb;10(2):48-56.

31. Rud J, Omnell KA. Root fractures due to corrosion: diagnostic aspects. Scand J Dent Res 1970;78(5):397-403.

32. Nair, MK.; Levin, MD.; Nair, UP. Radiographic interpretation. In: Hargreaves K, Berman L, editors. Cohen's pathways of the pulp. First South Asia ed. St. Louis: Elsevier; 2016. p. 33-70.

33. KhedmatS, Rouhi N, DrageN,Shokouhinejad N, Nekoofar MH. Evaluation of three imaging techniques for the detection of vertical root fractures in the absence and presence of guttapercha root fillings. Int Endod J 2012 Nov;45(11):1004-1009.

34. Chavda R, Mannocci F, Andiappan M, Patel S. Comparing the in vivo diagnostic accuracy of digital periapical radiography with cone-beam computed tomography for the detection of vertical root fracture. J Endod 2014 Oct;40(10):1524-1529.

35. Metzger Z, Berman LH, Tamse A. Cracks and fractures. In: Hargreaves K, Berman L, editors. Cohen's pathways of the pulp. First South Asia ed. St. Louis: Elsevier; 2016. p. 793-817.

36. Chang E, Lam E, Shah P, Azarpazhooh A. Cone-beam computed tomography for detecting vertical root fractures in endodontically treated teeth: a systematic review. J Endod 2015 Nov;42(2):177-185. 